\title{
USING DYNAMIC OPTIMAL POWER FLOW TO INFORM THE DESIGN AND OPERATION OF ACTIVE NETWORK MANAGEMENT SCHEMES
}

\author{
Simon GILL \\ University of Strathclyde, Scotland \\ simon.gill@strath.ac.uk
}

\author{
Graham W. AULT \\ University of Strathclyde, Scotland \\ graham.ault@strath.ac.uk
}

\author{
Ivana KOCKAR \\ University of Strathclyde, Scotland \\ ivana.kockar@strath.ac.uk
}

\begin{abstract}
Active Network Management (ANM) schemes are providing the communications and control infrastructure to allow the integration of energy storage and flexible demand in distribution networks. These technologies can be characterised as intertemporal in that their operation at different points in time is linked. This paper provides a discussion of the issues created when optimising an ANM scheme containing intertemporal energy technologies. A technique called Dynamic Optimal Power Flow is discussed and a case study is presented. The requirement to use forecasts of renewable energy resources such as wind power is discussed together with the issues that this creates.
\end{abstract}

\section{INTRODUCTION}

The principle of Active Network Management (ANM) is leading to a change in how distribution networks are operated [1]. The communications and control technology inherent in an ANM scheme provide the ability to monitor and control distribution networks and distributed generation in close to real time and to communicate varying schedules to connected devices.

The first generation of ANM schemes apply the philosophy of monitor and control. This involves the measurement of network parameters and the use of these measurements as control signals. The time scale for implementation of ANM control signals is of the order of several seconds to several tens of seconds, for connected device response, placing ANM between protection and SCADA based controls. An example of an ANM scheme is the Orkney Smart Grid project [2], [3] which has the objective of increasing the capacity of renewable generation that can connect to a network and managing that generation within network constraints. The process of optimising these networks can be achieved by studying a small number of scenarios such as high renewable generation with low demand, and vice versa. Network settings are then applied in a way which will make the most effective use of prevailing conditions whilst honouring contractual obligations.

A second generation of ANM schemes are now being developed that go beyond the simpler real time monitor and control principle and use technologies that require advanced forecasting and scheduling. An example is the use of energy storage, the optimal operation of which requires planning in advance of operation. Optimising the use of such intertemporal energy technologies requires the use of forecasts of renewable generation and system demand, and the combination of these with traditional network optimisation techniques such as those found in Optimal Power Flow.

This paper discusses the issues associated with optimising a distribution network with intertemporal energy technologies. It discusses 'Dynamic Optimal Power Flow' as a tool for optimisation distribution networks and provides a case study based on an ANM scheme behind developed on the Shetland Islands, UK.

\section{ACTIVE NETWORKS AND INTERTEMPORAL TECHNOLOGIES}

Intertemporal technologies are those whose operation at one point in time affects their operation at other points in time. The consequence is that a decision to operate in a particular manner now will affect that ability of that technology to operate later. The issues this creates can be summarised by the question: Future operation is uncertain and current operation affects future operation; how should operation be planned across a particular time-horizon?

This over-arching question can be broken into a number of constituent questions regarding the planning and optimisation of such schemes:

\section{Over what time horizon will the system be optimised?}

The ability to plan and optimise the operation of an intertemporal technology depends on the availability of forecasts for conditions on the network. For example, if the objective is to maximise the use of renewable generation using a battery, the battery should be scheduled to charge when renewable generation is high and discharge when it is low. Forecasts of wind generation are only available over a period of hours or days, and the longer the forecast period, the lower the accuracy of the forecast is likely to be. A decision needs to be taken on what length of time schedules will be created for, will the schedules be updated on a rolling basis, or should the schedule be allowed to run out before a new schedule is created?

2. How are forecasts of renewable generation and system demand to be created and used?

As scheduling relies on forecasts, and forecasts are inherently uncertain, it is important to consider how forecast data is used. The simplest methodology for wind 
power forecasting is to take an off-the-shelf wind speed forecast and to make the naïve assumption that the forecast is correct, then convert wind speeds to power via a simple power curve and use these values directly in an optimisation. Under some circumstances this may provide enough information with which to operate. In other cases errors in the forecasts may lead to undesirable outcomes in network operation. An example is when wind speeds are forecast to be close to the 'shut-down' level of a wind farm. A small error in the wind speed forecast can make a significant difference to the power generated and therefore potentially a significant difference in the optimal schedule.

3. How is the system benchmarked, and what 'base case' is it compared against?

Benchmarking the system is important. The key criterion is that the use of forecasts and advance schedules should lead to an improvement in terms of meeting the objective under actual conditions. It is conceivable that the use of inaccurate forecasts could result in a worse situation than a base case. This should only occur occasionally, for example when the forecast errors are particularly large. The base case for comparison could be the network without the intertemporal energy technologies, or with those technologies operated in a fixed schedule. It is important that the benchmarking is clear and well defined to allow useful comparisons to be drawn regarding the success of the scheduling method.

\section{Examples of Intertemporal Energy Technologies:}

Energy Storage has already been mentioned as an intertemporal energy technology. Intertemporal constraints are created by the storage capacity and by operational or contractual rules. Charging or discharging can only be carried out for a finite time before limits on the State of Charge (SOC) are reached. So charging during one period reduces the remaining ability to charge before discharging must occur. Contractual arrangement such as requiring an energy store to be returned to a predefined SOC at the end of an operational period can impose additional constraints

The control of flexible demand can be achieved by a variety of models several of which are inteteporal in nature. For example, the timing of the delivery of energy to a load may be controlled by an ANM scheme with a requirement to deliver a particular quantity of energy across a day. The Shetland ANM scheme will involve a number of flexible demand devices which fit this model: domestic storage heating and a large scale electric boiler with heat storage [4], [5].

Some forms of dynamic line ratings will have intertemporal properties. For example line rating could be increased for short time periods as long as they are then reduced for long enough that the conductors re-cool.

\section{Optimisation Intertemporal ANM schemes}

The task of optimising an ANM scheme with intertemporal technologies must combine network constraints with the intertemporal characteristics of the controlled devices. It is assumed that a time frame is chosen (optimisation-horizon) over which the system is to be optimised, and this is divided into separate timesteps. A summary of the features needed in the optimisation is as follows:

- The ability to create an optimal schedule with demands/generation for each device at each timestep across an optimisation horizon;

- network constraints such as those included in an Optimal Power Flow problem applied at each timestep;

available renewable generation levels for each timestep, calculated from forecasts;

- the ability to curtail renewable generation when required and to apply principles-of-access when multiple non-firm generators are used [6];

- additional intertemporal constraints linking each time-step; and

- system wide stability constraints, for example linking the total level of renewable generation to the total conventional generation. This is particularly important when considering islanded networks [4].

\section{DYNAMIC OPTIMAL POWER FLOW}

The combining of the unit-scheduling requirements and network information in an optimisation can be achieved by an extended form of Optimal Power Flow (OPF). Dynamic Optimal Power Flow (DOPF) extends OPF to multiple time-steps which are linked by the creation of additional intertemporal variables and constraints. The formulation of a DOPF is similar to that of an OPF [7]. An objective function, $f$, is minimized:

$$
\min \{f(x(t), \tau(t))\}
$$

Where $x(t)$ represents the standard OPF variables defined at each time-step and $\tau(t)$ are the additional intertemporal variables. The minimisation is applied subject to the following constraints:

$$
\begin{gathered}
g(x(t), \tau(t)) \leq 0 ; h(x(t), \tau(t))=0 \\
k(x(t), \tau(t)) \leq 0 ; l(x(t), \tau(t))=0
\end{gathered}
$$

Here, $g$ and $h$ are the OPF constraints consisting of the power flow equations, nodal energy balance, power lines and generator limits. The intertemporal constraints form $k$ and $l$.

The objective of the DOPF can be chosen in any way that can be formulated analytically. For example the objective can be to maximise renewable generation across the optimisation-horizon. Care must be taken when defining the objective to ensure that the results represent a truly physical optimal solution. An example of when a poorly constructed objective can cause problems occurs when using inefficient energy storage. If the objective is set purely to maximise the use of renewable generation, the optimisation will try to over-use the energy storage, 
cycling renewable generation through the store and losing excess energy in the inefficiencies.

\section{USING DOPF TO INFORM ANM DESIGN}

This section provides a case study of the application of DOPF to an ANM scheme. It is based loosely on the 'NINES' project being developed on the Shetland Islands distribution network [4], [5]. However, the values used for network components are illustrative and do not represent the parameters of the actual scheme itself; sizes and value have been changed to best exemplify some of the key concepts discussed.

Fig 1 shows an outline of the islanded distribution network on Shetland. The network voltage is $33 \mathrm{kV}$ and included three generation stations: Lerwick Power Station (LPS), Sullom Voe Terminal (SVT) and Burradale Firm wind farm. The objective of the ANM scheme is to increase the capacity of wind generation connected to the network under non-firm connection agreements and to maximise the use of the renewable generation available. A non-firm (NF) connection is one in which the generator can be compelled to curtail its generation on the command of the network operator. The example modelled for this paper includes:

- 2 additional 5MW NF wind farms; at Lerwick and Burradale; the Burradale NF wind farm has priority over the Lerwick wind farm;

- a 1MW 6MWh battery connected at Lerwick;

- a unit of flexible electrical storage heating connected at Lerwick. Consisting of 5MW and 20MWh of installed capacity;

- conventional generation unit costs are modelled as simple quadratic cost-curves. LPS is at all times cheaper than SVT; and

- a network stability rule is imposed that constraints the system to operate with a fixed percentage of total generation to be provided by Lerwick Power Station.

The parameters used for these devices in the optimisation are given in Table 1, and time-series of normalised forecast demand and wind generation are shown in Figure 2.

The objective of the optimisation is to minimise an arbitrary 'cost' function which consists of the quadratic costs of the conventional generation and linear costs of the two non-firm wind farms. Note that these are not real costs but functions which differentiate between generation from different sources: wind farms costs are significantly smaller than the conventional generation so will be used in preference to conventional generation. The two wind farms have different cost parameters: Burradale NF Wind Farm has lower cost that the Lerwick Wind Farm; this applies the priority order.

The DOPF problem is set up to consist of 96 fifteen minute periods and represents a 24 hour optimisationhorizon. Figure 3 shows the available, generated and curtailed wind at the two non-firm wind farms for the

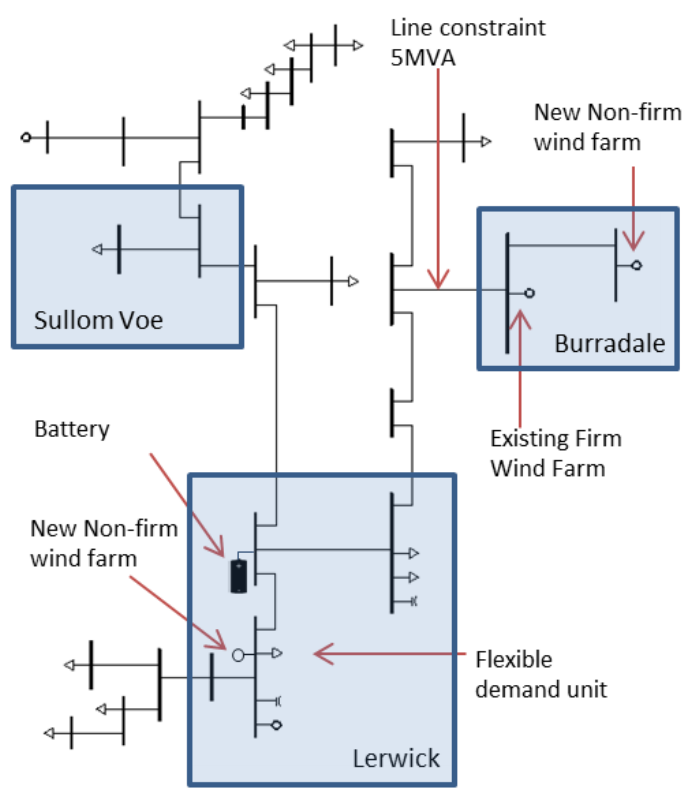

Figure 1: Outline diagram of the Shetland $33 \mathrm{kV}$ distribution network including ANM components

Table 1: Constraints and characteristics of case study components

\begin{tabular}{|c|c|}
\hline $\begin{array}{l}\text { ANM } \\
\text { Component }\end{array}$ & Constraints applied \\
\hline Network & Standard OPF constraints applied at each time-step \\
\hline LPS & $\begin{array}{l}\text { Minimum generation: } 0 \mathrm{MW} \\
\text { Maximum generation: } 50 \mathrm{MW} \\
\mathrm{C}(\mathrm{P})=\text { 'Cheap' }\end{array}$ \\
\hline SVT & $\begin{array}{l}\text { Minimum Generation: } 5 \mathrm{MW} \\
\text { Maximum Generation: } 25 \mathrm{MW} \\
\mathrm{C}(\mathrm{P})=\text { 'Expensive' }\end{array}$ \\
\hline $\begin{array}{l}\text { Existing } \\
\text { Burradale } \\
\text { Wind farm }\end{array}$ & $\begin{array}{l}\text { Firm Connection. } \\
\text { Generation varies with wind profile across } \\
\text { optimisation horizon }\end{array}$ \\
\hline $\begin{array}{l}\text { New Lerwick } \\
\text { Wind Farm }\end{array}$ & $\begin{array}{l}\text { Non-firm connection } \\
\text { Generation varies with wind profiles across } \\
\text { optimisation horizon } \\
C(P)=0.02 P \text { Low Priority NF generator }\end{array}$ \\
\hline $\begin{array}{l}\text { New Burradale } \\
\text { Wind Farm }\end{array}$ & $\begin{array}{l}\text { Non-Firm Connection } \\
\text { Generation varies with wind profiles across } \\
\text { optimisation horizon } \\
C(P)=0.01 P \text { High Priority NF Generator }\end{array}$ \\
\hline Battery & $\begin{array}{l}\text { Minimum State of Charge }=0 \mathrm{MWh} \\
\text { Maximum State of Charge }=6 \mathrm{MWh} \\
\text { Maximum charge/discharge rate }=1 \mathrm{MW} \\
\text { Charge } / \text { discharge efficiency }=0.85 \\
\text { (Round Trip efficiency) }=0.72 \\
\text { Initial SOC }=\text { Final SOC }=3 \mathrm{MWh}\end{array}$ \\
\hline $\begin{array}{l}\text { Flexible } \\
\text { Demand }\end{array}$ & $\begin{array}{l}\text { Required energy delivery }=20 \mathrm{MWh} \\
\text { Maximum rate of delivery }=5 \mathrm{MW} \\
\text { Maximum Storage capacity }=20 \mathrm{MWh} \\
\text { Initial SOC }=\text { Final SOC }=10 \mathrm{MWh}\end{array}$ \\
\hline
\end{tabular}

optimal solution.

The curtailment applied to wind farms in this case-study arises from two sources: power flow constraints local to Burradale and the network stability rule. The local curtailment occurs for example during time-step 33 and 34 where the Burradale NF wind farm is curtailed and the Lerwick wind farm continues to generate. The priority order does not force the curtailment of a low priority 


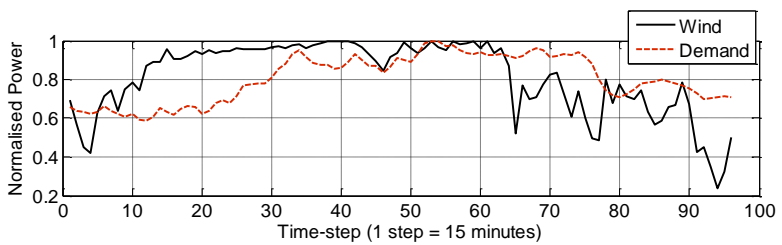

Figure 2: Normalised wind and system demand across the 24 hour optimisation horizon
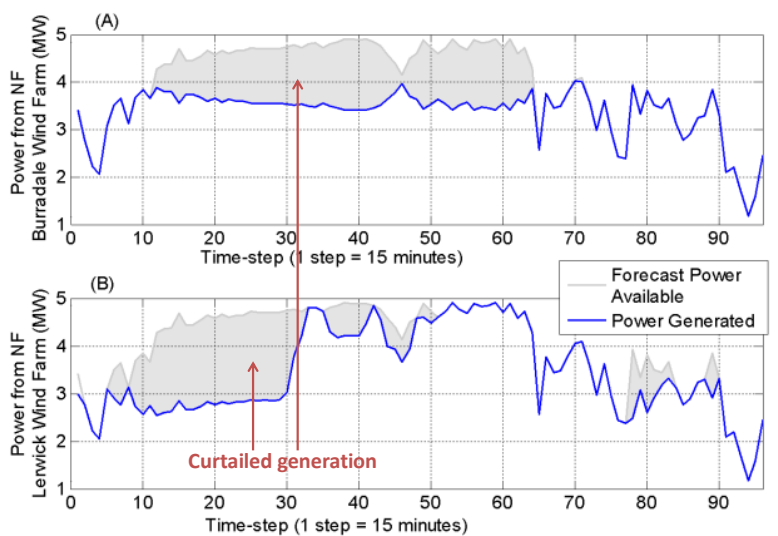

Figure 3: Schedules for generation from (A) the high priority nonfirm generator at Burradale and $(B)$ the low priority generator at Lerwick.
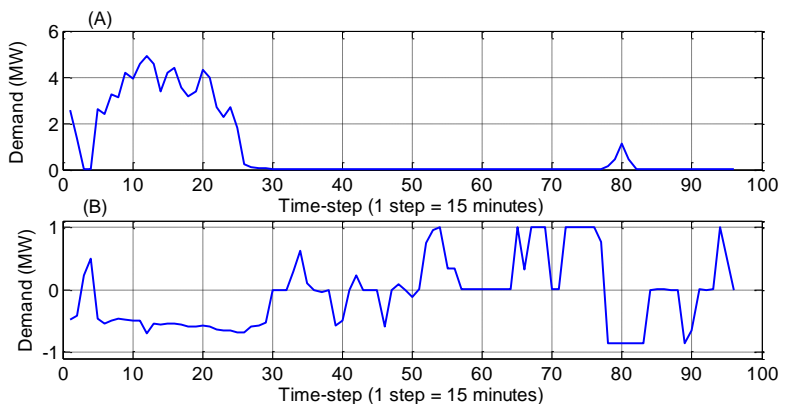

Figure 4: Schedules for (A) flexible demand unit and (B) Energy Storage. Positive numbers represent demand from the network

generator if it is not contributing to a constraint. The network stability constraint applies, for example, at around period 80 , during this time-step the low priority generator is curtailed but not the high priority generator. Both constraints apply at the same time during many of the time-steps

\section{USING DOPF TO INFORM ANM DESIGN}

The results of a DOPF simulation provide a useful tool for the design of scheduling schemes in ANM; however they should not be implemented directly. As noted above the results assume the forecasts of generation and demands are correct, i.e. the forecast provides perfect foresight. Considering wind forecasts, Figure 5 shows the relationship between wind speed forecasts for 6 hours ahead and the conditions that actually occurs. The data is for a UK coastal location, and the scatter is overlaid with a grid representing the different sections of a simple wind turbine power curve.

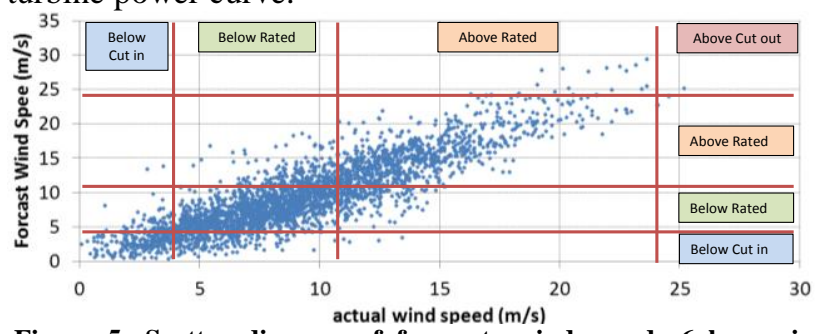

Figure 5: Scatter diagram of forecasts wind speeds 6 hours in advance and the actual wind speeds.

The location of points within the sections of the power curve for forecast and actual values gives an idea of the areas of difficulty that can arise. The points which fall within 'Above rated' on both forecast and actual axis will be points with relatively good power forecasts as any wind speed between the wind turbine's rated and cut-out wind speed should result in a similar power output. In contrast, the 'Below Rated' region represent a region where differences between forecast and actual wind speed will be manifest as an error in forecast power. More difficult still are points which fall in or near the 'Above Cut Out' region. Here, a small change in wind speed (For example from $23 \mathrm{~m} / \mathrm{s}$ to $25 \mathrm{~m} / \mathrm{s}$ ) can lead to a change in power output equal to the rated capacity of the wind farm. This small wind-speed error can have significant implications for the operation of ANM schedules.

This data provides a simple illustration of some of the problems that will be faced once forecast data is used in ANM schemes. Further research is needed into how to effectively use forecasts, to characterise the uncertainty and the effect of incorrect forecasts in ANM scheme operation.

\section{ACKNOWLEDGEMENTS}

The authors would like to acknowledge Scottish and Southern Power Distribution for this support of research, and the funding provided by EPSRC: EP/G037728/1.

\section{REFERENCES}

[1] BERR, 2008, "Active Network Management (ANM) Technology" online:webarchive.nationalarchives.gov.uk/20100919181607/http:/ www.ensg.gov.uk/assets/dgcg00104rep.pdf

[2] KEMA, 2012, "Smart Grid Strategic Review: The Orkney Islands Active Network Management Scheme" online: www.ssepd.co.uk/uploadedFiles/SSEPD Microsites/Orkney smart _grid/Controls;/Resources/SmartGridStrategicReview.pdf

[3] SSEPD, 2012 Orkney Smart Grid, online: http://www.ssepd.co.uk/OrkneySmartGrod/, accessed 12/12/2012

[4] M. J. Dolan, G. W. Ault, D. F. Frame, S. Gill, et al, "Northern Isles New Energy Solutions: Active Network Management Stability Limits", IEEE Power and Energy Society Innovative Smart Grid Technologies (Europe) 2012, Paper No, 376.

[5] M. J. Dolan, S. Gill, G. W. Ault, et al "Modelling and delivery of an active network management scheme for the northern isles new energy solutions project"

[6] R. Currie, B. O'Neill, C. Foote, et al, 2011, “Commercial arrangements to facilitate active network management", CIRED, Frankfurt

[7] S. Gill, G. Ault, I. Kockar, 2012, "Dynamic Optimal Power Flow for Active Distribution Networks" submitted to, Trans. Power Syst. 